\title{
Management of COVID-19 in a French Nursing Home: Experiences from a Multidisciplinary Mobile Team
}

\author{
P. Poupin ${ }^{1}$, D. N'Diaye ${ }^{2}$, F. Chaumier ${ }^{3,4}$, A. Lemaignen ${ }^{2}$, L. Bernard $^{2}$, B. Fougère ${ }^{1,5}$
}

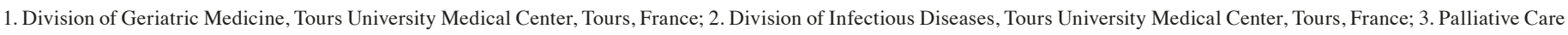

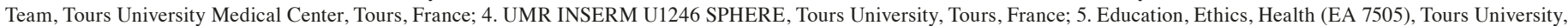
Tours, France.

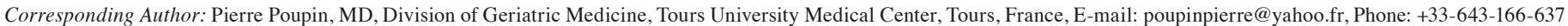

\begin{abstract}
BACKGROUND: Long-term residential care facilities and nursing homes are known to be particularly vulnerable to viral respiratory diseases and have expressed the need for multidisciplinary collaboration to help manage outbreaks when they occur.

METHOD: In April 2020, Tours University Medical Center created a multidisciplinary mobile team to help local nursing homes deal with outbreaks of coronavirus disease 2019 (COVID-19). The team included a geriatrician, infectious disease experts, and palliative care specialists. RESULTS: On April 8th, 2020, the first intervention took place in a 100 residents nursing home with a total of 18 confirmed cases among 26 symptomatic residents and five deaths. The nursing home staffs' main requests were a multidisciplinary approach, consensus decisionmaking, and the dissemination of information on disease management. CONCLUSION: Three lessons emerged from this collaboration: (i) intensify collaborations between hospitals and nursing homes, (ii) limit disease transmission through the use of appropriate hygiene measures, broad screening, and the isolation of sick residents and sick employees, and (iii) provide sufficient human resources.
\end{abstract}

Key words: Viral respiratory disease, outbreak, nursing home, multidisciplinary collaboration.

\section{Background}

I n December 2019, a previously unknown type of severe acute respiratory syndrome emerged in the city of Wuhan (China) (1). In January 2020, the pathogen was isolated and described as severe acute respiratory syndrome coronavirus 2 (SARS-CoV-2) (1). The corresponding disease (coronavirus disease 2019, COVID-19) spread rapidly around the world and prompted the World Health Organization to declare a global pandemic on March 11th, 2020 (2). In France, the outbreak was declared officially on March 15th, 2020.

Long-term residential care facilities and nursing homes (NHs) are known to be particularly vulnerable to viral respiratory diseases (e.g., influenza) $(3,4)$. Due to frailty and comorbidities, older adults are more likely to experience severe and/or complicated forms of COVID-19, with a higher mortality rate (5). In France, a total of 142,852 confirmed cases had been reported by May 28th, 2020 (6). Of these, 33,646 were $\mathrm{NH}$ residents (leading to 13,806 deaths (7)) and 16,215 were $\mathrm{NH}$ staff members.
An NH is primarily a place to live and secondarily a place to receive medical care. Faced with this unprecedented health crisis, Tours University Medical Center (Tours, France) created a mobile multidisciplinary team (MMT) to help affected NHs deal with COVID-19 in a coordinated manner. To the best of our knowledge, MMTs have rarely been used to deal with COVID-19 outbreaks among older adults in our country.

The objective of the present report is to share our experience of this novel collaboration between an $\mathrm{NH}$ and a university medical center's department of geriatric medicine.

\section{Method}

Over the last decade, the concept of a mobile geriatric team has emerged in France and other countries in response to the constant requirement for cost-effective medical care that optimizes resources. During the pandemic, our mobile geriatric team was redeployed for (i) nasopharyngeal swab testing of $\mathrm{NH}$ residents with suspicious symptoms, and (ii) operation of a phone hotline (from 9am to 6pm, seven days a week) for $\mathrm{NH}$ medical staff.

Although the French government provided guidance on preventing SARS-CoV-2 from spreading within NHs (the prohibition of visits by family members, the closure of communal dining rooms, the serving of meals in the residents' bedrooms, the suspension of group activities, etc.) and provided additional resources for $\mathrm{NHs}(8)$, it did not issue specific guidelines on how to manage an outbreak.

University medical centers have a role in coordinating and disseminating good practice in geriatric medicine within local NHs. In order to answer the most frequent requests from $\mathrm{NH}$ medical staff when an outbreak occurred (mainly information on disease management and on consensus decision-making for sick residents), the Geriatrics Department at Tours University Medical Center created a new entity: a multidisciplinary mobile team (MMT) comprising a geriatrician, two infectious disease experts, a palliative care nurse, and a palliative care physician. Each member's role is summarized in Figure 1; the objective was to provide appropriate care for each resident by drawing on the MMT members' expertise. 
Figure 1. The MMT: composition and roles

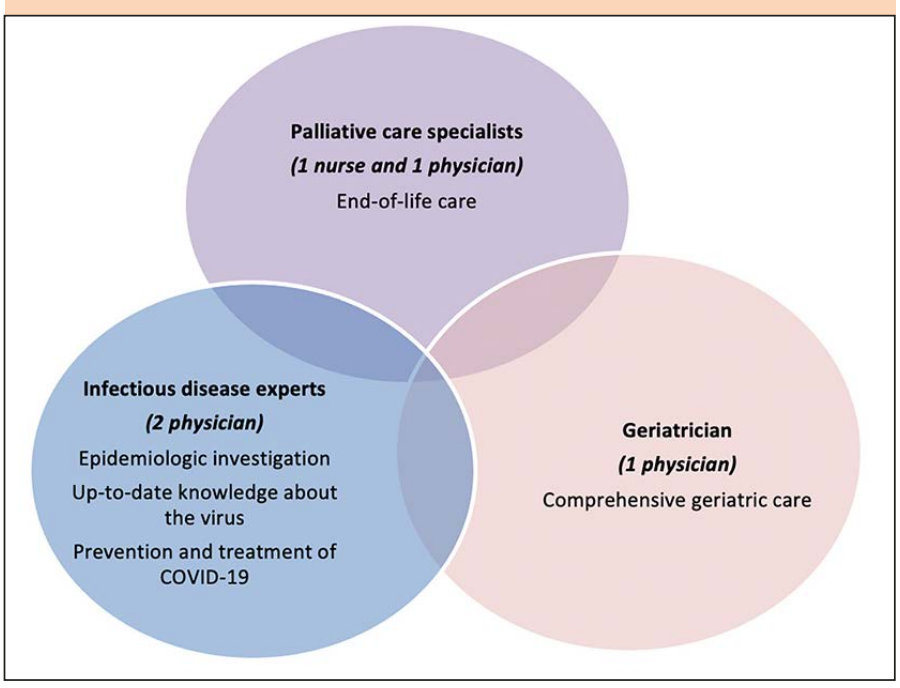

\section{Results}

On April 8th, 2020, the MMT's first intervention took place in a 100-resident $\mathrm{NH}$ in the city of Tours. It was one of the 4 seriously affected NHs in the local Indre et Loire area, which has about $60 \mathrm{NHs}$ in total. The MMT members and the NH's physician, head nurse and director had an initial 5-hour meeting, during which questions from the NH staff members alternated with instructive presentations by the MMT members (Figure 2).

Each of the three floors in the $\mathrm{NH}$ was divided into 2 units, and there were 60 care staff. The COVID-19 outbreak in the NH had started about 2 weeks previously, and the first confirmed case in a resident was recorded on March 23rd. The disease spread rapidly to all units, giving a total of 18 confirmed cases among 26 symptomatic residents and 6 among the staff. Five of the 18 SARS-CoV-2-positive residents had died at that point. The change in the number of cases of COVID-19 during the two weeks before the MMT's intervention is shown in Figure 3.

Although around half of the staff members had developed symptoms of COVID-19, a shortage of tests prevented us from confirming these suspected cases. It appeared that the first case of COVID-19 in the NH was a staff member who subsequently tested positive for SARS-CoV-2. The staff member had come to work with respiratory symptoms, had not used personal protective equipment (PPE), and had been in close contact with the first of the residents to fall ill. Furthermore, the lack of knowledge about the risk of SARS-CoV-2 transmission by asymptomatic carriers and the sometimes contradictory guidance on PPE use (the use of a face mask, primarily) had resulted in confusion and inadequate behavior among the care staff.

The MMT's infectious disease experts first outlined the procedures for outbreak management. The $\mathrm{NH}$ staff members were given detailed information on the mode of viral transmission and the main strategies for preventing further spreading: cohorting staff (to limit mixing and thus opportunities for transmission), limiting staff meetings or seminars, applying social distancing during staff meal breaks, and wearing face masks at all times. To preserve supplies, the use of PPE was optimized (2 disposable surgical face masks per day and per person). The MMT's main recommendations are summarized in Table 1.

With regard to specific medical care, the palliative care physician, the palliative care nurse, an infectious disease expert and the geriatrician were helped the NH's medical staff to discuss medical decisions for each resident. This included asking whether the residents or their legal guardian or family had provided with advanced directives, and deciding whether the NH was able to meet residents' medical needs. Even though most health facilities and hospitals were under pressure or even saturated, we considered that older patients should not be excluded from hospitalization on the basis of their age alone. We considered that hospital admission was relevant for patients

Figure 2. Structure of the initial meeting between the NH staff members and the MMT members

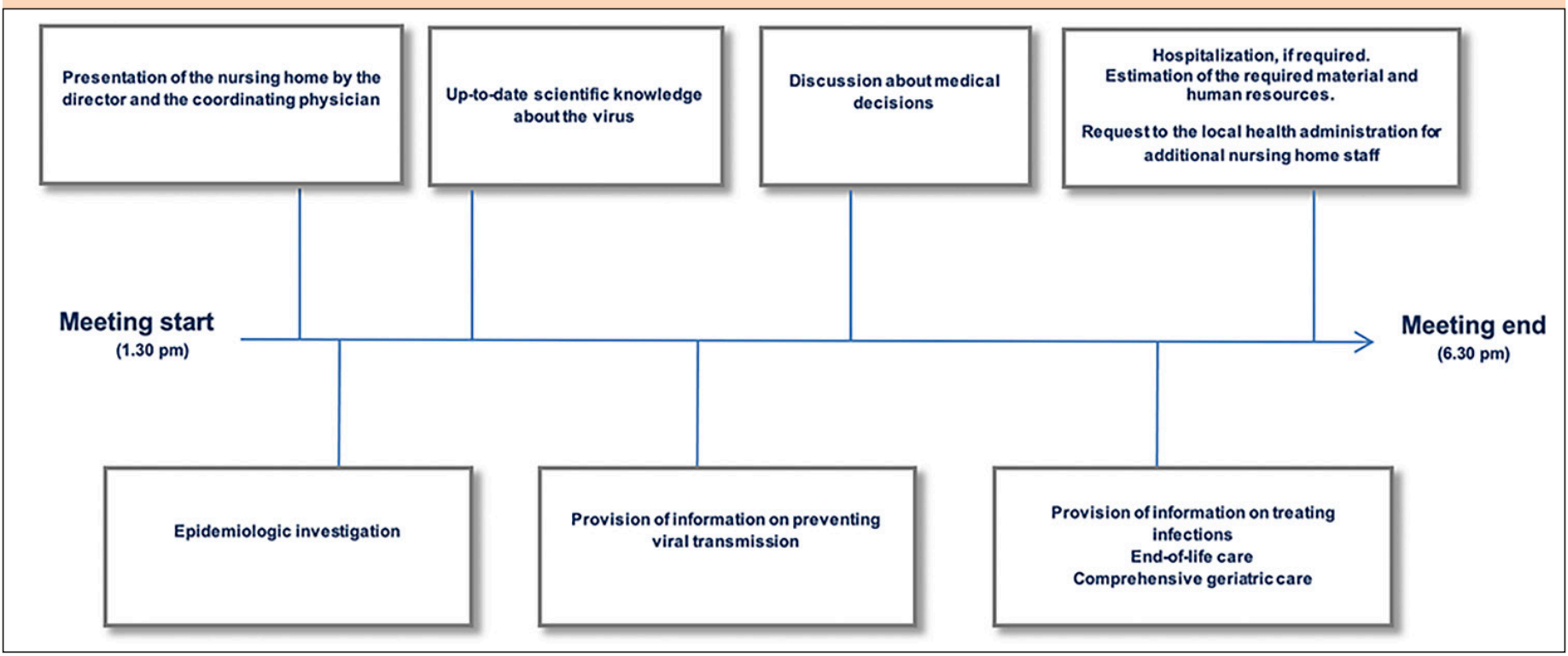


Table 1. Key recommendations by the MMT

\begin{tabular}{|c|c|}
\hline \multicolumn{2}{|c|}{ Recommendations on preventing transmission of the virus } \\
\hline \multirow[t]{4}{*}{ Recommendations concerning staff members } & $\begin{array}{l}\text { Staff cohorts: a team of nurses and nursing assistants for each ward, } \\
\text { with no mixing. } \\
\text { Limit contact between staff (only those contacts required for care } \\
\text { provision). }\end{array}$ \\
\hline & $\begin{array}{l}\text { Wear face masks at all time ( } 2 \text { per day and per person). } \\
\text { Apply social distancing. } \\
\text { Wash the hands regularly with an alcohol-based solution }\end{array}$ \\
\hline & $\begin{array}{l}\text { Note information on your symptoms, check your temperature at least } \\
\text { daily, and do not come to work if you have symptoms. }\end{array}$ \\
\hline & Clean and disinfect door handles and common areas regularly \\
\hline \multirow[t]{3}{*}{ Recommendations concerning residents } & $\begin{array}{l}\text { Encourage residents to wash their hands with an alcohol-based solu- } \\
\text { tion before every meal and regularly throughout the day. }\end{array}$ \\
\hline & $\begin{array}{l}\text { Keep all residents in their rooms. Create COVID-19 units for confir- } \\
\text { med cases. }\end{array}$ \\
\hline & $\begin{array}{l}\text { Isolate ill residents in their rooms and wear appropriate PPE during } \\
\text { care procedures (a gown, an apron, protective glasses or a protective } \\
\text { face shield, a face mask, and a hair net). Use biohazard bags. }\end{array}$ \\
\hline \multicolumn{2}{|c|}{ Recommendations on managing the increased burden of care } \\
\hline \multicolumn{2}{|c|}{ Home hospitalization units and local health administrations should provide more staff. } \\
\hline \multicolumn{2}{|c|}{ Ask residents (or their family or legal guardian) for advance directives. } \\
\hline \multicolumn{2}{|c|}{ Apply the decision tree published by the French Society of Geriatric Medicine and Gerontology9. } \\
\hline \multicolumn{2}{|c|}{$\begin{array}{l}\text { Hospitalize the resident if required. } \\
\text { If the case is treated in the } \mathrm{NH} \text { : check the indication for antibiotic therapy, the prevention of thromboembolic events, and the prevention of } \\
\text { undernutrition, dehydration and loss of functional autonomy. }\end{array}$} \\
\hline
\end{tabular}

Figure 3. Cases of COVID-19 among NH residents during the 2 weeks before the start of the MMT's intervention

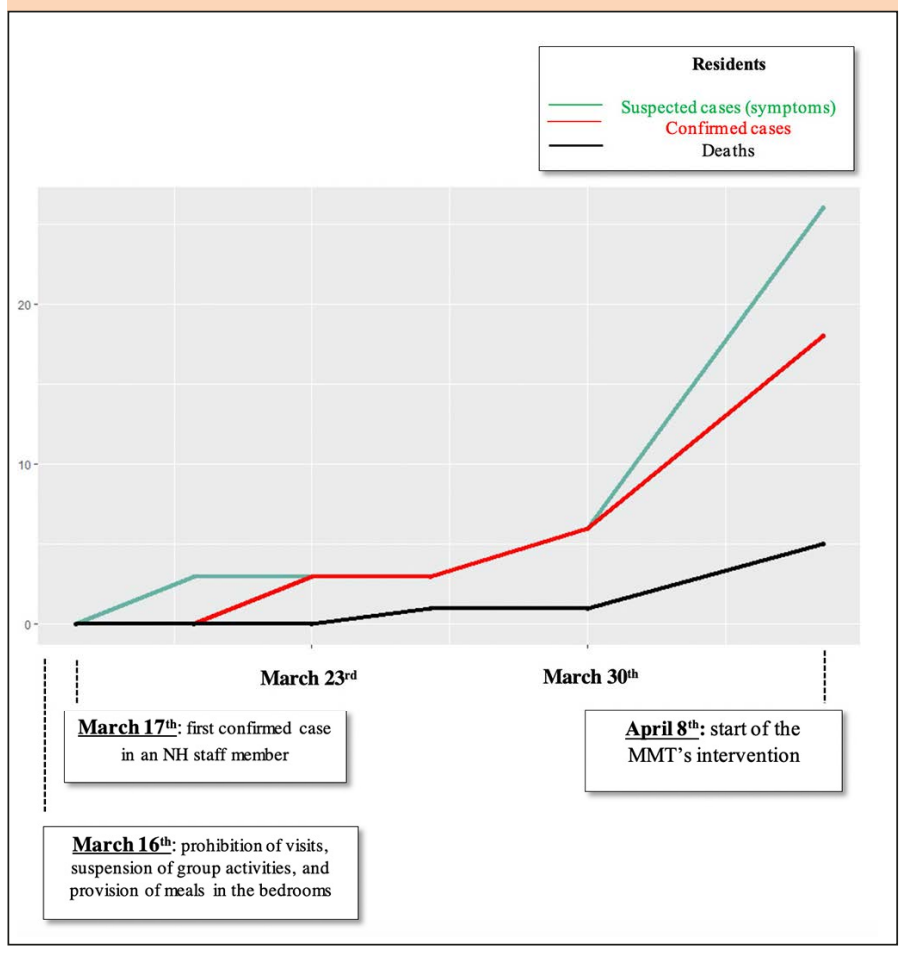

with few comorbidities or a low level of dependence when clinical or laboratory criteria for severity were met or when other diagnoses had to be ruled out. If the patient agreed, he/she was admitted to hospital.

The French Geriatric and Gerontology Society (9) had developed a decision tree for COVID-19. Although the MMT considered this decision tree, decisions on hospitalization or the level of care also took account of clinical common sense and discussions between the MMT, the NH's physician, and the head nurse. The patients and/or their legal guardian or family were kept informed about these discussions. In fact, most of the residents clearly expressed the wish to stay in their usual living environment (i.e. the $\mathrm{NH}$ ). In other cases, patients appeared to be too frail and too severely ill to benefit from hospitalization.

With regard to treatment, the MMT considered whether or not antibiotic treatment was necessary and emphasized the importance of preventing dehydration, undernutrition, and loss of functional autonomy. The MMT reviewed the NH's ability to provide oxygen therapy, palliative care, and end-of-life care. These procedures increased the burden of care and prompted the creation of COVID-19-only units.

\section{Discussion}

Four key issues emerged from the MMT's initial assessment: NH staff members (i) must know how to recognize the signs and symptoms of COVID-19, which are not the same in older adults as in younger adults, (ii) must be aware of how COVID-19 is transmitted and must use PPE appropriately; (iii) require information on patient management and a specific organizational structure for dealing with the COVID19 outbreak, and (iv) require help with discussing medical 
decisions and the level of care.

Following our intervention, three $\mathrm{NH}$ residents were immediately hospitalized. Local health administrations were asked to reinforce the NHs' staff. For example, scheduled surgical procedures in local hospitals and clinics were suspended and only emergency operations were carried out; this reduction in the level of activity freed up staff for temporary redeployment to NHs. Home hospital units also provided staff reinforcements for patients requiring a high level of care. The NH's stocks of PPE, drugs and medical equipment were considered to be sufficient.

Collaboration between healthcare professionals appears to be crucial for developing guidance on the management of COVID-19: it combines the NH staff members' knowledge of their residents and expertise in allocating resources within their own facilities, the geriatrician's approach to caring for frail, older adults, the palliative care specialist's expertise in end-of-life care, and the infectious disease specialist's expertise on the management of infections. When an outbreak occurs, this emergency situation disrupts the NH's organization. The NH staff member must then focus on acute medical care - a situation for which they are not prepared and which requires collaborative, adaptive strategies. The collaboration also improved our expertise in outbreak management. For example, screening for SARS-CoV-2 with a reverse transcriptase polymerase chain reaction (RT-PCR) assay (using nasopharyngeal swabs) became much more widely available about a week after our intervention in the NH. The NH's coordinating physician and director asked all the residents and staff members to be tested. The screening detected a number of asymptomatic carriers among the residents and employees.

The residents who tested positive were isolated in a dedicated unit for two weeks or until they tested negative. The staff members who tested positive were asked to stay at home for two weeks. This broad nasopharyngeal swab screening program appeared to be very useful for controlling the outbreak. However, sensitive but less painful tests would be needed for regular testing, the detection of asymptomatic employees or residents, and thus the prevention of viral transmission. Approximately one month after all the NH staff and residents had been screened, the outbreak had been stabilized and no new cases were recorded.

\section{Conclusions}

Nursing homes are extremely vulnerable to contagious viral respiratory diseases such as COVID-19. Outbreaks can be dramatic, and preventing the virus from spreading is a priority (10). The COVID-19 pandemic has highlighted the need for collaboration between NHs and other health care facilities (11). The lessons that emerged from this initial collaboration can be summarized as followed:
1) Guidelines may help with consensus decision-making, the dissemination of information, and multidisciplinary collaboration.

2) Transmission of the virus must be limited by adopting appropriate hygiene measures (e.g. protective face masks), screening all $\mathrm{NH}$ residents and employees with an RT-PCR assay, and isolating all confirmed cases.

3) Sufficient human resources must be deployed quickly in these exceptional circumstances.

We hope that this feedback will help the authorities to provide useful, precise, specific guidelines on all aspects of managing COVID-19 outbreaks in NHs. A multidisciplinary MMT approach may help to develop appropriate strategies in NHs.

Acknowledgements: The authors thank the staff of the nursing home in which the intervention took place for their incredible dedication to the residents' care. We thank Dr. David Fraser (Biotech Communication SARL, Ploudalmézeau, France) for copy-editing assistance and Eliane Sabourin for proofreading the manuscript.

Funding sources: This research did not receive any specific funding from agencies in the public, commercial, or not-for-profit sectors.

Conflicts of Interest: Dr. Adrien Lemaignen reports other from Gilead, non-financial support from Pfizer, personal fees from MSD, outside the submitted work. Pr Louis Bernard, Pr Bertrand Fougère, Dr Diama N'Diaye, Dr Chaumier and Dr Pierre Poupin declared no conflicts of interest.

\section{References}

1. Zhu N, Zhang D, Wang W, et al. A novel coronavirus from patients with pneumonia in China, 2019. N Engl J Med 2020; 382:727-733.

2. World Health Organization. Rolling updates on coronavirus disease (COVID-19) 2020 (https://www.who.int/emergencies/diseases/novel-coronavirus-2019/events-asthey-happen. opens in new tab). Accessed May 30, 2020

3. Hand J, Rose EB, Salinas A, et al. Severe respiratory illness outbreak associated with human coronavirus NL63 in a long-term care facility. Emerg Infect Dis 2018; 24:1964-6

4. McMichael TM, Currie DW, Clark S, et al. Epidemiology of Covid-19 in a LongTerm Care Facility in King County, Washington. N Engl J Med. 2020;382:20052011.

5. Wang L, He W, Yu X. Coronavirus disease 2019 in elderly patients: characteristics and prognostic factors based on 4-week follow-up. J Infect. 2020 Jun;80(6):639-345.

6. World Health Organization. Coronavirus disease 2019 (COVID-19): situation report - 111. May 28, 2020. (https://www.who.int/docs/default-source/coronaviruse/ situation-reports/20200528-covid-19-sitrep-129.pdf?sfvrsn=5b154880_2). Accessed May 30,2020.

7. French Public Health Agency. COVID19. Weekly epidemiological record, 29 may 2020. (French). (https://www.santepubliquefrance.fr/maladies-et-traumatismes maladies-et-infections-respiratoires/infection-a-coronavirus/documents/bulletinnational/covid-19-point-epidemiologique-du-29-mai-2020). Accessed May 30, 2020.

8. French ministry of solidarity and health. Strategy for the care of the older adults in nursing homes and at home in the context of COVID-19 epidemic. https://solidaritessante.gouv.fr/IMG/pdf/strategie-prise-en-charge-personnes-agees-covid-19.pdf Accessed May 30, 2020.

9. French Geriatric and Gerontology Society. Collegial decision support https://sfgg.org/actualites-covid-19/prise-en-charge-en-ehpad/ Accessed April 8, 2020

10. Tan LF, Seetharaman S. Preventing the Spread of COVID-19 to Nursing Homes: Experience from a Singapore Geriatric Centre. J Am Geriatr Soc. 2020;68(5):942.

11. Stall NM, Farquharson C, Fan-Lun C et al. A Hospital Partnership with a Nursing Home Experiencing a COVID-19 Outbreak: Description of a Multi-Phase Emergency Response in Toronto, Canada. J Am Geriatr Soc. 2020, 2020 Jul;68(7):1376-1381.

How to cite this article: P. Poupin, D. N'Diaye, F. Chaumier, et al. Management of COVID-19 in a French Nursing Home: Experiences from a Multidisciplinary Mobile Team. J J Frailty Aging 2021;10(4)363-366; http://dx.doi.org/10.14283/jfa.2021.16 